\title{
Social inclusion level of Spanish and foreign adolescents: Proposal for an evaluation instrument
}

\author{
Manuel Moyano ${ }^{1} \cdot$ Roberto M. Lobato $^{2}$ (D) $\cdot$ Petya Ventsislavova ${ }^{3} \cdot$ Humberto M. Trujillo $^{4}$ \\ Accepted: 13 November 2020 / Published online: 18 November 2020 \\ (C) Springer Science+Business Media, LLC, part of Springer Nature 2020
}

\begin{abstract}
Social exclusion is one of the most complex and sensitive social problems nowadays. Of all social groups, adolescents are among the most vulnerable to social exclusion, which can interfere with their social development. Consequently, the evaluation of this construct in adolescents is an important matter. The aim of this investigation was to develop the Social Inclusion for Adolescents Scale (SIAS). Firstly, five psychosocial factors were proposed, which potentially contribute to social inclusion: (1) covered needs, (2) self-efficacy, (3) social support, (4) job training, and (5) social integration. From these five factors, a set of items was created and reduced using qualitative evaluations. The final set of items was used in three studies, with a Spanish population $(N=$ $1540)$ and a foreign population $(N=460)$, to test the psychometric properties of the scale, its dimensional structure, the measurement invariance between Spanish and foreign people, the reliability of the instrument and the evidence of the validity of its measurements. The results indicate that this scale is psychometrically reliable enough to assess social inclusion in adolescents.
\end{abstract}

Keywords Scale $\cdot$ Social inclusion $\cdot$ Social exclusion $\cdot$ Youth $\cdot$ Psychometric properties

Social exclusion is one of the most complex and sensitive social problems that countries must face. In this sense, the economic crisis has led to an increase in inequality (OECD, 2019), reducing the financial capacity of certain groups that have suffered a deterioration in their living conditions (Abebe, Tøge, \& Dahl, 2016) and the indicators of subjective wellbeing (Navarro-Carrillo, Valor-Segura, \& Moya, 2019). Likewise, the so-called refugee crisis (Postelnicescu, 2016) has highlighted critical aspects related to multiculturalism (Chin, 2017), such as difficulties in integrating immigrant groups or the resurgence of anti-immigration movements that have encouraged discourses of hate and discriminatory acts (Greven, 2016).

Roberto M. Lobato

romulobato@gmail.com

1 Department of Psychology, University of Cordoba, Cordoba, Spain

2 Research \& Projects Department, Euro-Arab Foundation for Higher Studies, C/ San Jerónimo, 27, 18001 Granada, Spain

3 Department of Psychology, Nottingham Trent University, Nottingham, Great Britain

4 Department of Methodology for Behavioral Sciences, University of Granada, Granada, Spain
According to EUROSTAT, in 2019, approximately 21.9\% of Europeans were at risk of social exclusion, especially for young people, with a specific rate of $29.2 \%$. EUROSTAT data indicate that the percentage of people at risk of exclusion in Spain is $26.1 \%$, i.e., above the European average. These figures are convergent with the preliminary data of the Survey of Living Conditions of the Spanish Institute of Statistics (2019), a survey conducted in 2018, when there was an increase in relative poverty that reached $21.5 \%$ of the population, affecting mostly young people between the ages of 16 and 29 years $(28.3 \%)$. In addition, the unemployment rate has already exceeded $15 \%$ in Spain, having reached a peak of more than $26 \%$ of the active population in previous years, which places Spain as one of the developed countries with the highest unemployment rates (OECD, 2019). However, each social group seems to be affected in a different way, since some groups are more vulnerable than others, and these are the ones in which it would be advisable to intensify preventive actions. According to the Red Cross social vulnerability report (Rúa, Martínez, Redondo, Ortiz, \& Fabra, 2019), prototype profiles could be established depending on the levels of vulnerability. Thus, the highest levels of vulnerability seem to be related to different groups: women, youth (16-24), uneducated people, foreigners, and unemployed people.

Therefore, foreigners are more vulnerable to social exclusion, especially immigrants and refugees. According to the 
United Nations Refugee Agency (UNHCR, 2019), in 2018, more than 70 million trips took place, which is the highest figure ever recorded. About 26 million of those migrants were refugees, and more than half of them were under 18. In the context of Western societies, these groups may be especially vulnerable to social exclusion, facing situations of harassment, prejudice, and discrimination. These difficulties to participate in society and to have access to fundamental rights, such as health, education and employment, make cultural barriers visible (European Union Agency for Fundamental Rights, 2019).

\section{Conceptualization of the Social Exclusion-Inclusion Continuum}

There are conceptual positions that emphasize different aspects of the social exclusion-inclusion continuum, such as the culture of those groups at risk of being excluded, the resources which people are deprived of (e.g., employment, education, citizenship, respect) and the problems related to the impact of social exclusion (e.g., low income, under-housing, health and injustice) (Du et al., 2020; Li, Zhao, \& Yu, 2018; Van Bergen et al., 2019; Van Regenmortel et al., 2016). Despite the different interpretations, most of these authors agree that the social exclusion-inclusion continuum is a multidimensional concept that refers to a process through which people lose or gain participation in society, whether in the economic, political, or relational fields. Therefore, we assume that it is a dynamic and interactive phenomenon that operates at various levels. Following this perspective, and taking into account the complexity and multidimensionality of the construct, some authors consider that it is never absolute and depends on the context. For example, Pirani (2013) defended this hypothesis searching for different social exclusion profiles in a large study. This author observed that the real risk of exclusion occurs when the person remains outside of three essential dimensions: institutional, economic and social. Moreover, he claimed that we should focus on the social, economic and cultural contexts to understand the risk factors in different regions.

In this vein, it is important to emphasize that, although the concept of poverty refers to the lack of certain resources to fulfil basic needs, generally economical ones, the concept of social exclusion transcends this conceptualization and goes beyond it. Even though this term initially emerged as a response to dissatisfaction with traditional reductionist approaches focused exclusively on poverty (i.e., lack of economic resources), it is still controversial and far from having an established definition. Thus, some authors have defined social exclusion as the difficulty to participate in socio-economic activities (Duffy, 1995; Paugam \& Russell, 2000); others have considered it as a denial of rights due to the discrimination to which certain social groups are subjected (Klasen, 2002;
Tholen \& De Vries, 2004), while it has also been customary to define it in terms of polarization or as an increasing intergroup distance (Esteban \& Ray, 1994).

\section{The Evaluation and Assessment of Social Inclusion}

Taking this into account, all of the above implies that the methodological approaches to evaluate and measure social inclusion have also been diverse. Firstly, different institutions have created indicators to assess it at macro and meso levels. From such approaches, empirical indicators linked, for example, to inequality and poverty have been systematized (Room, 1995). Social inclusion indices have also been proposed based on the distribution of certain indicators of the well-being of an individual and the prototypical thresholds of vulnerability (Tsakloglou \& Papadopoulos, 2002). Along the same lines, from quantitative axiomatic approaches, numerical weights have been assigned to different functionalities that have some impact on social inclusion (Chakravarty \& D'Ambrosio, 2006).

As we can see, there are different instruments to assess social inclusion, although there are no unique criteria and it is assumed that no measure is always appropriate for all studies or contexts. In this vein, Baumgartner and Burns (2014) argued that, although social inclusion is considered a key result for global mental health and psychosocial intervention policies and programs, its measurement is poorly developed. These authors analyzed five specific scales to measure social inclusion among populations with mental disorders, concluding that these instruments had limitations in the direct measurement of the construct, as well as in its application in cross-cultural contexts.

Likewise, Cordier et al. (2017) reviewed the psychometric properties of the instruments to evaluate social inclusion. Through a systematic search in different databases, they selected 25 evaluation instruments and a manual. The most common domains included in the measures were connectedness and a sense of belonging (21), followed by participation (19) and citizenship (10). The authors concluded that the general quality was variable, especially highlighting three tools: Social and Community Opportunities Profile-Short (Huxley et al., 2012), Social Connectedness Scale (Lee \& Robbins, 1995), and the Social Inclusion Scale (Secker, Hacking, Kent, Shenton, \& Spandler, 2009).

In short, the psychometric quality of the instruments available for measuring social inclusion is promising, although it needs further refinement (Baumgartner \& Burns, 2014; Cordier et al., 2017). As was seen in the literature review, there is a gap in the definition of the social inclusion construct, there is no agreement on the dimensions it encompasses, and the measures are tailored to specific groups, making its cross- 
cultural evaluation difficult. Therefore, it is necessary to consider: (1) advancing in a universal definition of social inclusion for ongoing research; (2) developing instruments specially adapted to the different stages of evolutionary development; (3) integrating the different dimensions that constitute social inclusion; and (4) taking into account cross-cultural differences in the measures.

\section{The Present Research}

When we refer to social inclusion, we expect that there is a higher probability for this to happen where the possibilities to participate in different social fields (economic, political and relational, among others) are high. By extension, when we talk about the fact that a person or group is at risk of social exclusion, we mean that there are a series of indicators that suggest that such exclusion is more likely. In addition, the usefulness of having indicators to assess social inclusion is closely related to the political and social strategies that should be applied.

Taking into account the above considerations, in this research we define social inclusion as a process of commitment and effective participation in society as a means to improve the quality of life, cover basic needs, reduce social isolation and improve the sense of belonging.

As we have already argued, from a psychosocial point of view, social inclusion is a multidimensional process in which numerous factors can be considered influential and could be operationalized and quantified. Our proposal is based on the assumed process and multicomponent definition, as well as on the bibliographic review carried out, and will encompass five factors. These are: (1) needs covered, both primary and second-order, which implies the perception of the level of coverage or satisfaction of different material and affective aspects of daily life; (2) self-efficacy, broadly understood as the perception of having a series of personal resources such as self-confidence, self-control, tolerance to frustration and self-esteem, which will be essential to optimize how individuals cope with life's difficulties daily, and therefore, with social participation; (3) social support, whether real or perceived (perception of the possibility of being helped by other people), which will be a relevant indicator of the relational aspect of inclusion; (4) job training or, more specifically, the positive expectations of obtaining basic training and finding a job in the future; and (5) social integration, defined as the expectations related to the positive approach to society, as well as to the personal commitment to it.

Theoretically, it could be considered that, at higher levels of needs covered, self-efficacy, social support, job training, and social integration, there will be greater social inclusion. In this way, the person will have a set of psychosocial resources (real and perceived) to face, minimize, or avoid, where appropriate, exclusion, and thus participate more actively and adaptively in society.

Therefore, this investigation was focused on the development of an instrument to assess social inclusion in Spanish and foreign adolescents of different religions and genders (hereinafter Social Inclusion for Adolescents Scale: SIAS). Specifically, the research aims of this study were: (1) to develop a scale of social inclusion in adolescents; (2) to analyze the psychometric properties of the scale in a sample of adolescents residing in Spain; (3) to explore and confirm the factor structure of the scale; (4) to confirm the measurement invariance of the scale between Spanish and foreign adolescents; (5) to obtain evidence of the validity and reliability of the measuring instrument; and (6) to assess whether there are differences in the factors that potentially contribute to social inclusion based on different sociodemographic variables; in this case, nationality, gender and religion.

\section{Study 1}

In this first study, we explored the psychometric properties and internal consistency of the SIAS. Furthermore, we analyzed the proposed dimensions and determined its validity. In order to accomplish this latter objective, we expected to find out that women (vs. men), foreigners (vs. Spanish people), and non-Christians (vs. Christians) presented lower levels of social inclusion.

\section{Method}

\section{Participants}

Four hundred and forty-six high school students (224 women) aged between 12 and 24 years $\left(M_{\text {age }}=15.10, S D_{\text {age }}=1.10\right)$ were surveyed through incidental sampling. All the high schools were located in Spanish neighborhoods with medium-high levels of marginality. Regarding nationality, half of the participants were Spanish $(N=223)$ and the other half were foreigners $(N=223)$ from Morocco $(51.57 \%)$, Ecuador (19.28\%), Romania (12.11), and Colombia (6.71\%), each of the other nationalities constituted less than $1 \%(10.33 \%)$. Regarding religion, $69.98 \%$ of the respondents defined themselves as Christians, $18.74 \%$ as Muslims, $2.48 \%$ as members of other religions, and $8.80 \%$ as non-believers.

\section{Evaluation Instrument}

Based on the definitions of the factors described in the introduction section (needs, self-efficacy, social support, job training, and social integration), we developed a preliminary set of 90 items presented as affirmative statements. For the 
qualitative evaluation of the initial set of 90 items, we followed a flexible process that lasted approximately two months, with the participation of the following agents: (1) a group of students of Secondary Education $(N=14)$, (2) two experts in multicultural education, (3) three researchers, and (4) two philologists. Different focus groups and interviews were conducted to review the items, removing redundant ones and discarding those that could generate problems of content or understanding. Once the process was completed, we selected 24 items from the original 90 items. They included empirical indicators of each of the five factors proposed. Thus, the final instrument consists of two parts: (1) a 24-item multidimensional scale on factors which potentially contribute to social inclusion, and (2) questions about sociodemographic variables (i.e., gender, age, nationality and religion).

\section{Procedure}

Participation in the study was voluntary. The survey was completed in approximately $30 \mathrm{~min}$ in the usual classrooms of the students with the collaboration of the teaching staff of the corresponding high school. Previously, the corresponding permission had been requested from the management teams of the educational centers.

\section{Results}

Firstly, a statistical analysis of the items was carried out. Secondly, a study of the factor structure of the instrument was carried out, in which the Main Axes procedure was applied with Equamax rotation. Thirdly, some indices related to the reliability of the instrument were calculated. Fourthly, some analyses were conducted to obtain evidence of the external measurement validity of the instrument. Specifically, the correlations between the factors were calculated and the influence of the sociodemographic variables (i.e., gender, nationality and religion) on the scoring of the scale factors was analyzed through multiple comparisons of means. Lastly, comparisons were carried out between the means obtained in each of the factors of the scale; the sociodemographic variables taken into account in these comparisons were nationality (Spanish vs. foreigner), gender (man vs. woman) and religion (Christian, Muslim, other, non-religious).

\section{Statistical Analysis of the Items}

Taking into account the indications of different authors (Lord \& Novick, 1968), in the first statistical analysis of the 24 items of the scale, we calculated the arithmetic mean, the standard deviation, the item-total correlation of each item, and Cronbach's alpha if the item had been discarded (see
Table 1; the English and Spanish versions of the items are in the Annex). Cronbach's alpha of the scale was .86. Additionally, the analysis showed that alpha did not increase with the removal of any of the items.

\section{Factor Structure}

Firstly, the Kaiser-Meyer-Olkin (KMO) sample adequacy index was calculated and Bartlett's sphericity test was performed. The KMO index showed a value of 0.85 , while Bartlett's test was statistically significant $\left(\chi^{2}=2803.26\right.$, $p<.001)$. These data suggest that the factor analysis was viable and relevant.

Then, a first-order exploratory factor analysis was performed on the total sample $(N=446)$. The Main Axis procedure was performed with Equamax rotation; factors with eigenvalues greater than 1 were considered. The resulting factor structure was made up of a total of five factors that jointly explained $39.37 \%$ of the total variance (see Table 1). The first factor explained $10.10 \%$ of the total variance and corresponded, theoretically, to the Self-efficacy dimension. The second factor explained $8.41 \%$ of the total variance and corresponded to the Covered Needs dimension. The third factor explained $7.02 \%$ of the variance and corresponded to the Social Support dimension. The fourth factor explained $6.93 \%$ of the variance and corresponded to the Social Integration dimension. Finally, the fifth factor explained $6.89 \%$ of the total variance and corresponded, theoretically, to the Job Training dimension.

All items showed a saturation greater than 0.30 , except for item 21 (i.e., "When the moment comes, I would like to have a family and live here in Spain"; .261), which also showed a low communality $\left(\mathrm{h}^{2}=.12\right)$. The decision to preserve it was motivated by the conceptual importance of this item.

\section{Reliability}

Based on the proposed dimensionality set forth above, the overall internal consistency was evaluated through Cronbach's alpha for the total scale $(\alpha=.86)$. Subsequently, Cronbach's alpha was calculated for each of the subscales of the instrument, which ranged between .63 and .82 . These internal consistency indicators interpreted as a whole provided initial evidence of acceptable instrument reliability.

\section{Evidence of Validity}

Table 2 shows the correlations between the factors of the SIAS, distinguishing between the subgroup of Spanish people $(N=223)$ and the subgroup of foreign people $(N=223)$. As expected, the different factors of the instrument, as well as the average score of all items on the social inclusion scale, showed a positive and statistically significant correlation, which can be considered as evidence of convergent validity. 


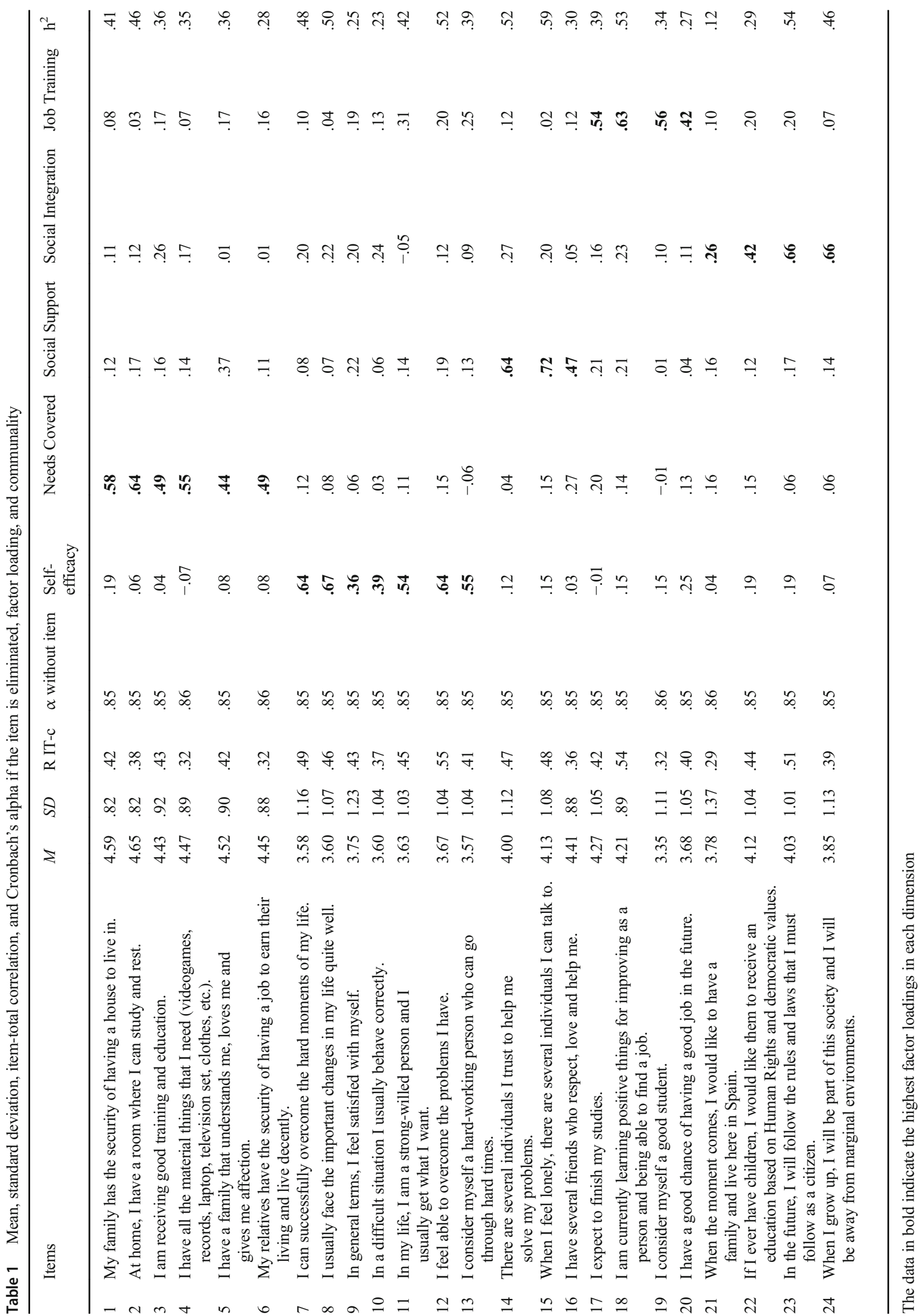


Table 2 Pearson correlations, mean, and standard deviation for Spanish (values above the diagonal) and foreigners (values below the diagonal)

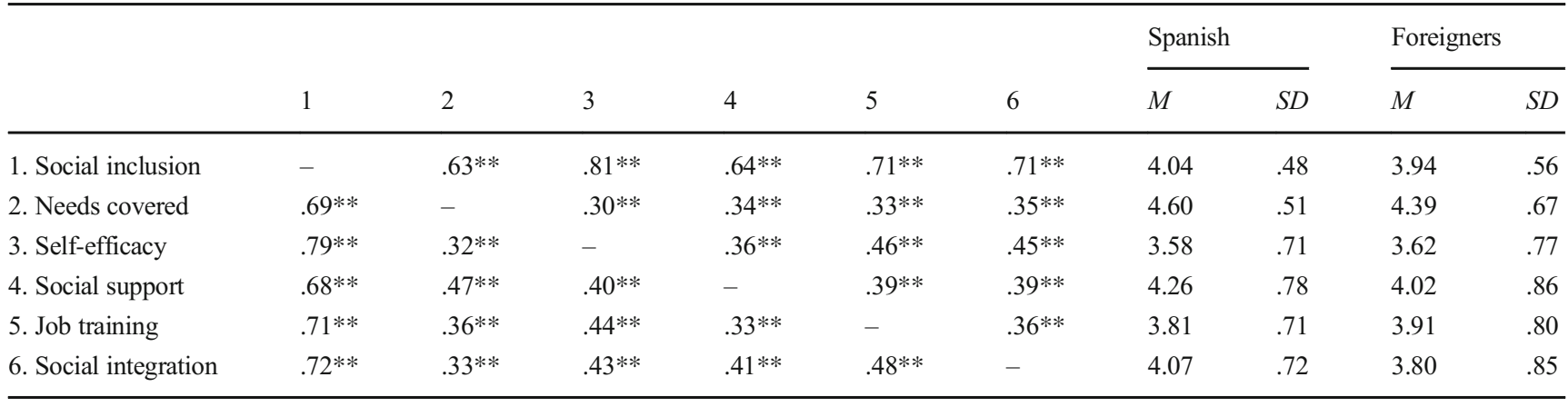

${ }^{*} p<.05 ; * * p<.01$

Then, the relationships between different sociodemographic variables and the SIAS were analyzed. Regarding gender, the results indicate that there were statistically significant differences in self-efficacy $(t=3.60, p<.001)$ and social support $(t=2.46, p<.001)$. Women $(M=3.49, S D=.78)$ presented lower scores in the self-efficacy dimension than men $(M=$ $3.74, S D=.66)$, while men $(M=4.04, S D=.86)$ presented lower scores in social support than women $(M=4.23, S D=.80)$.

As for nationality, statistically significant differences were found in needs covered $(t=3.62, p<.001)$, social support $(t=$ $3.07, p<.001)$, and social integration $(t=3.55, p<.001)$. The foreign group presented lower scores in needs covered $(M=$ $4.39, S D=.67)$, social support $(M=4.02, S D=.86)$ and social integration $(M=3.80, S D=.85)$ than the Spanish group $(M=$ $4.60, S D=.51 ; M=4.26, S D=.78 ; M=4.07, S D=.72$ ).

Finally, an ANOVA was also performed to assess differences based on religion. Statistically significant differences were found in covered needs $\left(F_{(3.439)}=5.85, p<.001\right)$, social support $\left(F_{(3.439)}=5.61, p<.001\right)$ and social integration $\left(F_{(3.439)}=6.97, p<.001\right)$. Post-hoc Tukey comparisons revealed statistically significant differences in needs covered between Christians and Muslims, with Muslims $(M=4.31$, $S D=.71)$ perceiving to have less needs covered than Christians $(M=4.57, S D=.52)$. Likewise, compared to Christians $(M=4.24, S D=.78)$, non-believers $(M=3.82$, $S D=.97)$ scored statistically significantly lower in social support. In the case of social integration, non-believers $(M=3.58$, $S D=.96)$ and members of other religions $(M=3.18, S D=$ 1.04) presented lower scores than Christians $(M=4.00$, $S D=.73$ ), while members of other religions presented lower scores than Muslims $(M=3.92, S D=.82)$.

\section{Discussion}

As expected, the exploratory factor analysis showed a fivefactor structure. The 24-item scale presented five dimensions: needs covered, self-efficacy, social support, job training, and social integration. Each of them presented a good internal consistency in the sample of Spanish nationals and foreigners. Finally, all factors were correlated, and foreigners and members of religions other than Christianity presented lower rates of social inclusion. Regarding gender, men and women presented lower scores in different dimensions, which highlights different dimensions of risk for each group. These results indicate that the social exclusion-inclusion continuum is multidimensional and that any group is susceptible to being at risk.

\section{Study 2}

Once the psychometric properties of the scale were proven and evidence of its measurements' validity was obtained, the second study was aimed at proving the dimensional structure of the Social Inclusion for Adolescents Scale (SIAS) in a large sample.

\section{Method}

\section{Participants}

A large sample of 1080 Spanish high school students $(590$ women) aged between 12 and 25 years $\left(M_{\text {age }}=15.53\right.$, $S D_{\text {age }}=1.87$ ) were surveyed through incidental sampling. All the high schools were located in Spanish neighborhoods with medium-high levels of marginality. Regarding religion, $75.00 \%$ of the respondents defined themselves as Christians, $10.90 \%$ as Muslims, $1.00 \%$ as members of other religions, and $13.10 \%$ as non-believers.

\section{Evaluation Instrument}

We used the 24 items of the SIAS developed in this research. The responses were measured on a 5-point Likert scale ranging from 1 (Fully disagree) to 5 (Fully agree), where higher scores indicate a higher social inclusion. We also included 
some questions about sociodemographic variables (i.e., gender, age, nationality and religion).

\section{Procedure}

The survey was completed in approximately $30 \mathrm{~min}$ in the usual classrooms of the students with the collaboration of the teaching staff of the corresponding high school. The procedure was the same as in the previous study.

\section{Results}

Firstly, a confirmatory factor analysis (CFA) was performed using the lavaan R package (Rosseel, 2012). Then, the internal consistency of the different factors included in the scale was explored. Finally, evidence of the scale's convergent validity was obtained through the factor correlations. All results are presented below in this order.

\section{Factor Structure}

In order to confirm the dimensional structure of the SIAS, a confirmatory factor analysis was performed. We created two models to test. The first model presented a unidimensional scale with all items. The second model presented the fivefactor structure obtained in the previous study. For a better evaluation of the parameters of the models and, taking into account the recommendations of several authors (Brown, 2006; Hair, Anderson, Tatham, \& Black, 1999; Hambleton, 1994), various indices were considered simultaneously.

Firstly, the assumption of multivariate normality was computed. As it showed multivariate kurtosis (Mardia's normalized coefficients of 125.53), we decide to test the three models with CFA using maximum likelihood estimator with robust estimation (Satorra-Bentler scaling corrections; Satorra \& Bentler, 2001). We found that the indices of Model 2 $\left(\chi_{(242)}^{2}=70.76, p<.001, \mathrm{CFI}=.907, \mathrm{TLI}=.894\right.$, RMSEA $(90 \% \mathrm{CI})=.053(.049-.057), \mathrm{SRMR}=.049, \mathrm{AIC}=$ $61,211.05)$ fitted better than those of Model $1\left(\chi_{(252)}^{2}=\right.$ 2279.16, $p<.001, \mathrm{CFI}=.611, \mathrm{TLI}=.574$, RMSEA $(90 \%$ $\mathrm{CI})=.107(.103-.111), \mathrm{SRMR}=.096, \mathrm{AIC}=63,511.50)$.

\section{Reliability}

The overall internal consistency was evaluated through Cronbach's alpha $(\alpha=.88)$. Subsequently, Cronbach's alpha was calculated for each of the subscales of the instrument, which ranged between .66 and .84 . These internal consistency indicators interpreted as a whole provided initial evidence of acceptable instrument reliability.

\section{Evidence of Validity}

Table 3 shows the correlations between the factors of the SIAS $(N=1049)$. As expected, the different factors of the instrument showed a positive and statistically significant correlation. This can be considered as evidence of convergent validity between the evaluated factors. Moreover, we included the average score of all items on the social inclusion scale, which showed a strong correlation with all subfactors.

Then, the relationships between different sociodemographic variables and scale factors were analyzed. Regarding gender, we found significant differences in needs covered $(t=4.64, p<.001)$, self-efficacy $(t=4.52, p<.001)$ and social support $(t=6.33, p<.001)$. Specifically, men presented lower scores in needs covered $(M=4.52, S D=.63)$ and social support $(M=4.13, S D=.87)$ than women $(M=4.68$, $S D=.47 ; M=4.45, S D=.74)$, while women presented lower scores in self-efficacy $(M=3.61, S D=.73)$ than men $(M=$ $3.81, S D=.69$ ). Finally, regarding religion, we found significant differences in needs covered $\left(F_{(3,1076)}=5.42, p=.001\right)$, social support $\left(F_{(3,1076)}=10.41, p<.001\right)$ and social integration $\left(F_{(3,1076)}=11.41, p<.001\right)$. In the case of needs covered, Muslims $(M=4.42, S D=.78)$ presented lower scores than Christians $(M=4.63, S D=.52)$ and non-believers $(M=4.60$, $S D=.51)$. In the case of social support, again, Muslims $(M=$ 3.92, $S D=.97)$ presented lower scores than Christians $(M=$ $4.35, S D=.77)$ and non-believers $(M=4.36, S D=.84)$. Finally, in the case of social integration, non-believers $(M=$ 3.89, $S D=.80)$ presented lower scores than Christians $(M=$ $4.26, S D=.65)$ and Muslims $(M=4.21, S D=.81)$.

\section{Discussion}

The results confirmed the five-factor structure in a large sample of Spanish adolescents. We also found similar internal consistency for all the factors. Regarding the evidence of convergent validity, all factors presented medium correlations among them and strong correlations with the total mean score of the SIAS, and men and Muslims showed more risk of social

Table 3 Pearson correlations, mean, and standard deviation

\begin{tabular}{llllllll}
\hline & 1 & 2 & 3 & 4 & 5 & $M$ & $S D$ \\
\hline 1. Social inclusion & - & & & & & 4.14 & .49 \\
2. Needs covered & $.67^{* * * *}$ & - & & & & 4.61 & .55 \\
3. Self-efficacy & $.79^{* * * *}$ & $.27^{* * *}$ & - & & & 3.71 & .72 \\
4. Social support & $.63^{* * *}$ & $.48^{* * *}$ & $.32^{* * *}$ & - & & 4.31 & .82 \\
5. Job training & $.73^{* * *}$ & $.34^{* * * *}$ & $.51^{* * *}$ & $.28^{* * *}$ & - & 3.97 & .73 \\
6. Social integration & $.70^{* * * *}$ & $.36^{* * * *}$ & $.39^{* * *}$ & $.36^{* * *}$ & $.47^{* * * *}$ & 4.20 & .70 \\
\hline$* p<.05 ; * * p<.01$ & & & & & & &
\end{tabular}


exclusion. As in the previous study, the results indicated that women presented less self-efficacy than men, and nonbelievers presented worse social integration than people with religious beliefs.

\section{Study 3}

Finally, in the third study, we aimed to explore the dimensionality of the scale in different groups. We chose Spanish and foreign adolescents, given that both are targets of social exclusion. In this study, we also aimed to determine the measurement invariance for both groups.

\section{Method}

\section{Participants}

We recruited a sample of Spanish and foreign people ( $N=$ 474, 255 women). The Spanish sample was formed by 237 high school students (125 women) aged between 12 and 25 years $\left(M_{\text {age }}=15.48, S D_{\text {age }}=1.76\right)$. Regarding religion, $75.90 \%$ of the respondents defined themselves as Christians, $10.50 \%$ as Muslims, $0.80 \%$ as members of other religions, and $12.70 \%$ as non-believers. The sample of foreigners was formed by 237 high school students (130 women) aged between 13 and $20\left(M_{\mathrm{age}}=15.46, S D_{\mathrm{age}}=1.45\right)$. Regarding religion, $38.80 \%$ of the respondents defined themselves as Christians, $38.00 \%$ as Muslims, $7.20 \%$ as members of other religions, and $16.00 \%$ as non-believers. Their nationalities were Moroccan $(34.70 \%)$, Ecuadorian (14.00\%), Romanian $(11.00 \%)$, Colombian $(8.50 \%)$, each of the other nationalities constituted less than $3 \%(31.80 \%)$.

\section{Evaluation Instrument}

We included the SIAS. The responses were measured on a 5point Likert scale ranging from 1 (Fully disagree) to 5 (Fully agree), where higher scores indicate a higher social inclusion. We also included some questions about sociodemographic variables (i.e., gender, age, nationality and religion).

\section{Procedure}

We followed the same procedure as in the previous studies. The measurement instrument was applied after the corresponding permission to different educational centers had been requested. The survey was completed in approximately $30 \mathrm{~min}$.

\section{Results}

We explored the factor structure in both groups: Spanish nationals and foreigners. Next, we tested the measurement invariance between the two groups. The lavaan $\mathrm{R}$ package was used to perform the estimation of the models (Rosseel, 2012). Then, we tested the internal consistency of each factor and, finally, we obtained evidence of the convergent validity by correlating the scale factors.

\section{Factor Structure}

To confirm the dimensional structure of the SIAS in Spanish nationals and foreigners, we performed a confirmatory factor analysis. Three models to test were created. The first model presented a unidimensional scale with all items. The second model presented the five-factor structure obtained in the previous study. Finally, as the fit was not entirely satisfactory, we presented a post-hoc model similar to Model 2, although with some covariances. Specifically, we controlled the covariance between items 7-8, 7-11, 17-18, and 6-21. The different models were tested separately for Spanish and foreign participants.

Spanish Sample Firstly, we proved the assumption of multivariate normality. As it showed multivariate kurtosis (Mardia's normalized coefficients of 50.80), we decided to test the three models with CFA using maximum likelihood estimator with robust estimation (Satorra-Bentler scaling corrections; Satorra \& Bentler, 2001). We found that Model 1 $\left(\chi_{(252)}^{2}=580.41, p<.001, \mathrm{CFI}=.638, \mathrm{TLI}=.603, \mathrm{RMSEA}\right.$ $(90 \% \mathrm{CI})=.093(.083-.103), \mathrm{SRMR}=.095, \mathrm{AIC}=$ 14,221.12) did not fit at all, while Models $2\left(\chi_{(242)}^{2}=\right.$ 285.18, $p=.030, \mathrm{CFI}=.954, \mathrm{TLI}=.947, \mathrm{RMSEA}(90 \%$ $\mathrm{CI})=.034(.012-.034), \mathrm{SRMR}=.062, \mathrm{AIC}=13,775.95)$ and $3\left(\chi_{(238)}^{2}=254.65, p=.219, \mathrm{CFI}=.982, \mathrm{TLI}=.980, \mathrm{RMSEA}\right.$ $(90 \% \mathrm{CI})=.021(.001-.040), \mathrm{SRMR}=.060, \mathrm{AIC}=$ $13,738.67)$ presented a good fit, although the AIC indicator showed a better fit for Model $3\left(\Delta \chi^{2}=26.90, p<.001\right)$ than Model 2. A diagram with item loads, item residuals, and latent variables covariances is shown in Fig. 1.

Foreigners Sample Again, the standardized estimate of multivariate kurtosis (Mardia's normalized coefficients of 25.26) suggested the use of the maximum likelihood method with robust estimation, thus we used the maximum likelihood estimator with robust estimation to test the three models. The results showed that Model $1\left(\chi_{(276)}^{2}=677.85, p<.001, \mathrm{CFI}=.575, \mathrm{TLI}=.534\right.$, RMSEA $(90 \%$ CI $)=.098(.090-.107)$, SRMR $=.101, \mathrm{AIC}=$ $15,228.56)$ did not fit at all, while Model $2\left(\chi_{(242)}^{2}=351.30\right.$, $p<.001, \mathrm{CFI}=.894, \mathrm{TLI}=.879, \mathrm{RMSEA}(90 \% \mathrm{CI})=.050$ $(.038-.061), \mathrm{SRMR}=.068, \mathrm{AIC}=14,825.64)$ was close to a good fit, and Model $3\left(\chi_{(238)}^{2}=304.17, p=.002, \mathrm{CFI}=.936\right.$, $\mathrm{TLI}=.925$, RMSEA $(90 \% \mathrm{CI})=.039(.024-.052)$, 


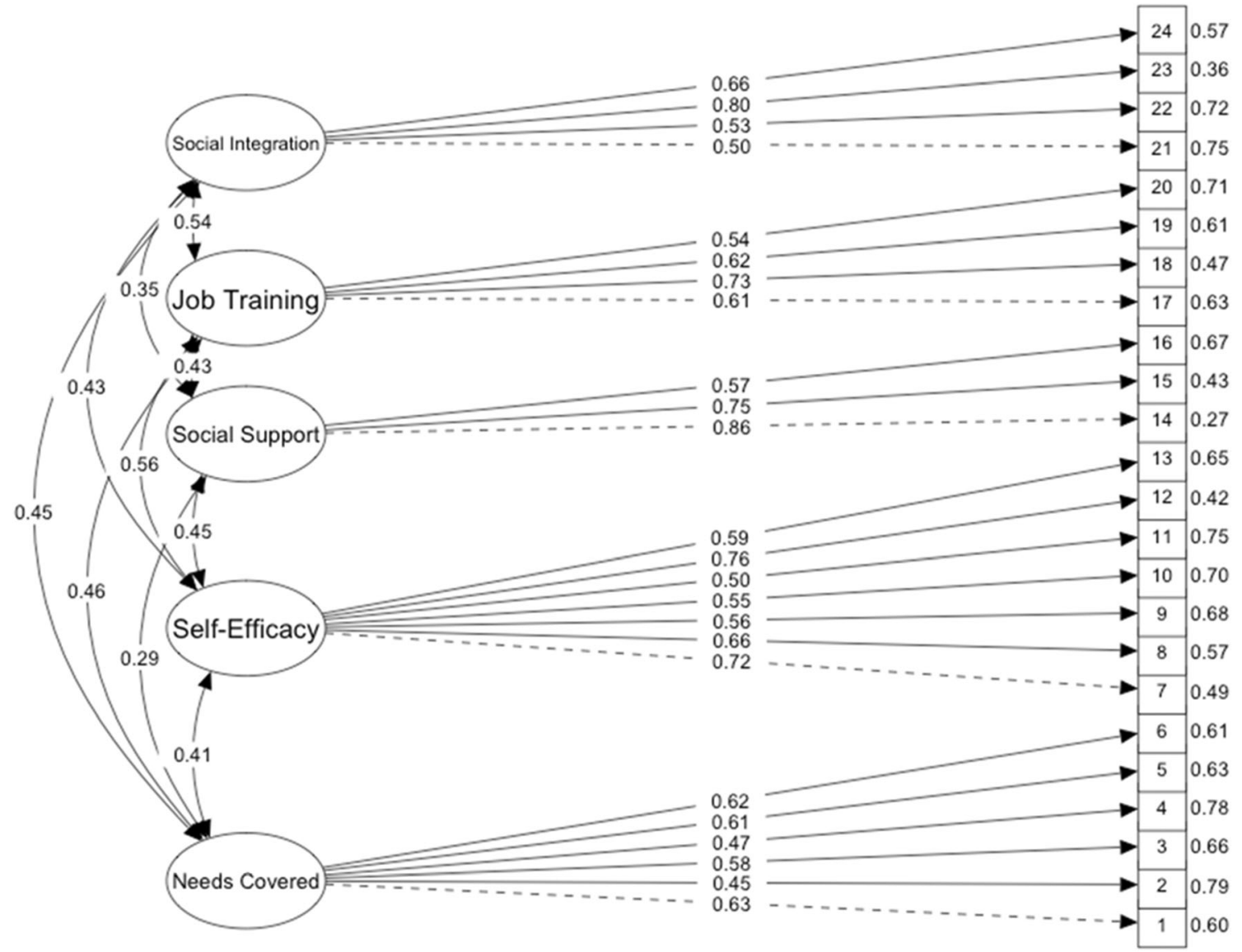

Fig. 1 Confirmatory factor analyses diagram for the Spanish sample

$\mathrm{SRMR}=.065, \mathrm{AIC}=14,774.93)$ presented a good fit. Overall, Model 3 presented a substantially better fit than Model $2\left(\Delta \chi^{2}=\right.$ $42.99, p<.001)$. A diagram with item loads, item residuals, and latent variables covariances is shown in Fig. 2.

\section{Measurement Invariance}

In order to evaluate the equivalence of the factor structure of the SIAS in its application to Spanish and foreign people, we tested the measurement invariance using Model 3 and the maximum likelihood method with robust estimation. We estimated an incremental model in which restrictions were added to the estimated parameters to show the configural, metric, and scalar invariance between groups.

The configural invariance $\left(\chi_{(476)}^{2}=742.09, p<.001\right.$, $\mathrm{TLI}=.892$, RMSEA $(90 \% \mathrm{CI})=.050(.043-.057)$, $\mathrm{SRMR}=.060, \mathrm{CFI}=.907)$ obtained appropriate fit statistics, thus we can say that the pattern of association of the items in each of the theorized factors was similar in both samples. In the case of the metric invariance $\left(\chi_{(495)}^{2}=773.43, p<.001\right.$, $\mathrm{TLI}=.891, \mathrm{RMSEA}(90 \% \mathrm{CI})=.050(.043-.057)$, $\mathrm{SRMR}=.065, \mathrm{CFI}=.902, \Delta \mathrm{CFI}=.005)$, the model reduced its fit levels $(\triangle \mathrm{CFI}<.01)$. Thus, we can conclude that the assumption of metric invariance is maintained (Cheung \&
Rensvold, 2002; Kline, 2016). In other words, it can be assumed that the factor loadings of the items associated with each factor are similar between Spanish and foreigner respondents. Finally, the fit of the scalar invariance $\left(\chi_{(514)}^{2}=850.19\right.$, $p<.001, \mathrm{TLI}=.873$, RMSEA $(90 \% \mathrm{CI})=.054(.048-.060)$, $\mathrm{SRMR}=.068, \mathrm{CFI}=.882, \Delta \mathrm{CFI}=.020)$ decreased $(\Delta \mathrm{CFI}>$ .01 ), which means that there was no scalar invariance. The intercepts of the items were different between the two groups.

\section{Reliability}

The overall internal consistency was evaluated through Cronbach's alpha for the Spanish $(\alpha=.87)$ and foreigner samples $(\alpha=.87)$. For the Spanish sample, the Cronbach's alpha of the subscales ranged between .72 and .81 , and, for the foreigner sample, between .68 and .79. These internal consistency indicators provided initial evidence of reasonable instrument reliability (Taber, 2018).

\section{Evidence of Validity}

Table 4 shows the correlations between the factors of the SIAS, distinguishing between the Spanish group $(N=223)$ and the foreigner group $(N=223)$. As expected, the different 


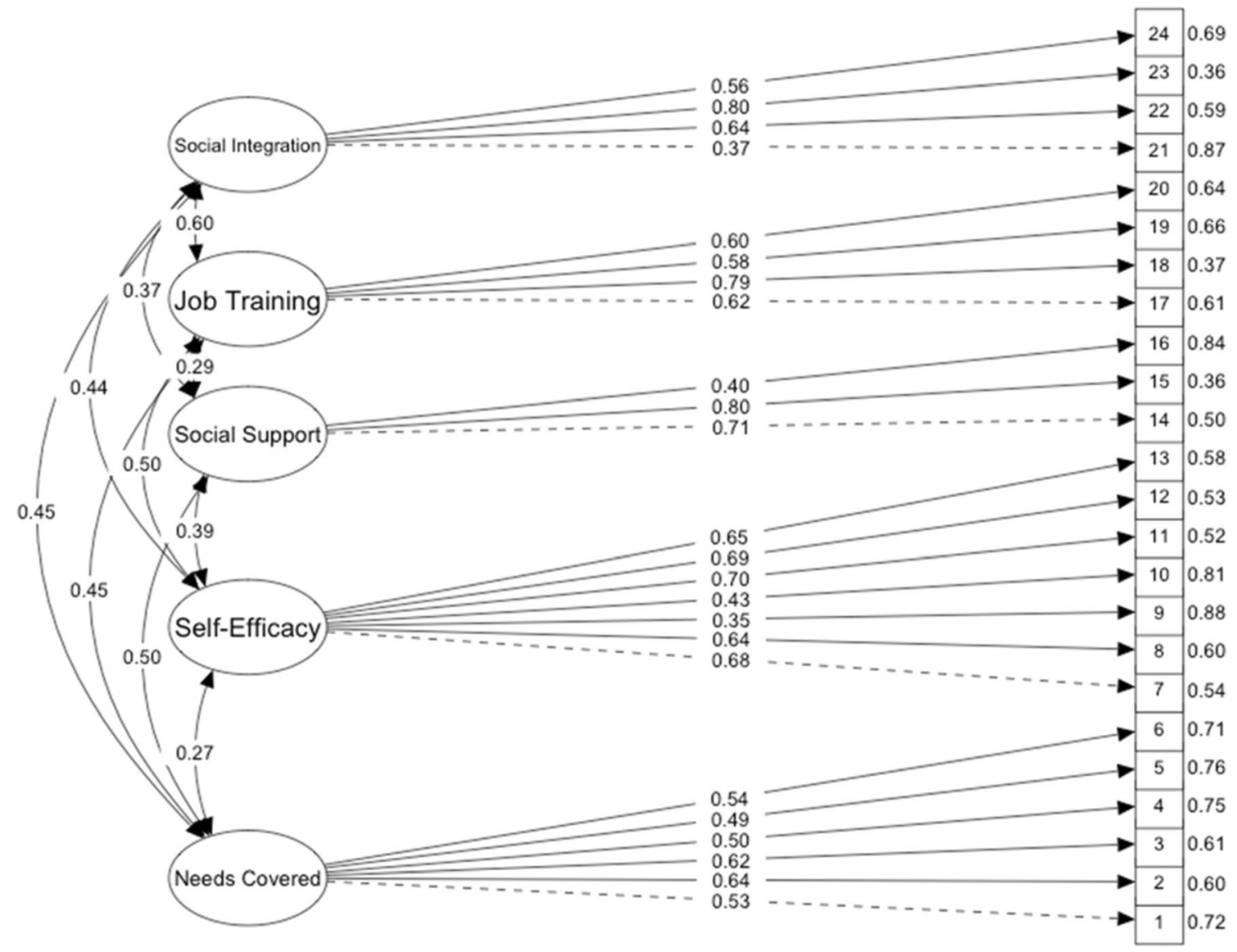

Fig. 2 Confirmatory factor analyses diagram for the foreigners sample

factors of the instrument showed a positive and statistically significant correlation. The total-scale factor showed a strong correlation with all subfactors again. This can be considered as evidence of convergent validity between the evaluated factors.

Finally, the relationships between different sociodemographic variables and scale factors were analyzed. We merged both samples to explore the differences in the sociodemographic variables. Then, two MANOVAs were carried out. In the first MANOVA $(2 \times 2)$, we included nationality
(Spanish vs. foreigner) and gender (man vs. woman) as independent variables. In the second MANOVA $(2 \times 4)$, we included nationality and religion (Christian, Muslim, other, non-believer). No significant interactions were observed, although we found simple effects in several of the social inclusion factors.

Regarding gender, we found significant differences in needs covered $(t=3.59, p<.001)$, social support $(t=3.33$, $p=.001)$ and job training $(t=3.21, p=.001)$. Specifically, men presented lower scores in needs covered $(M=4.37$,

Table 4 Pearson correlations, mean, and standard deviation for Spanish (values above the diagonal) and foreigners (values below the diagonal)

\begin{tabular}{|c|c|c|c|c|c|c|c|c|c|c|}
\hline & \multirow[b]{2}{*}{1} & \multirow[b]{2}{*}{2} & \multirow[b]{2}{*}{3} & \multirow[b]{2}{*}{4} & \multirow[b]{2}{*}{5} & \multirow[b]{2}{*}{6} & \multicolumn{2}{|c|}{ Spanish } & \multicolumn{2}{|c|}{ Foreigners } \\
\hline & & & & & & & $M$ & $S D$ & $M$ & $S D$ \\
\hline 1. Social inclusion & - & $.63^{* * * * *}$ & $.80^{* * * *}$ & $.61^{* * * *}$ & $.71^{* * * *}$ & $.63^{* * * *}$ & 4.15 & .48 & 3.96 & .052 \\
\hline 2. Needs covered & $.65^{* * *}$ & - & $.31^{* * * *}$ & $.26^{* * * *}$ & $.34^{* * * *}$ & $.32^{* * * *}$ & 4.63 & .51 & 4.34 & .72 \\
\hline 3. Self-efficacy & $.75^{* * *}$ & $.23^{* * * *}$ & - & $.35^{* * * *}$ & $.43^{* * * *}$ & $.31^{* * * *}$ & 3.71 & .73 & 3.68 & .75 \\
\hline 4. Social support & $.59^{* * * *}$ & $.41^{* * * *}$ & $.28^{* * * *}$ & - & $.33^{* * * *}$ & $.31^{* * * *}$ & 4.35 & .80 & 3.96 & .87 \\
\hline 5. Job training & $.69^{* * *}$ & $.34^{* * * *}$ & $.41^{* * * *}$ & $.25^{* * * *}$ & - & $.36^{* * * *}$ & 3.96 & .77 & 3.94 & .82 \\
\hline 6. Social integration & $.70^{* * * *}$ & $.32^{* * * *}$ & $.37^{* * * *}$ & $.34^{* * *}$ & $.50^{* * * *}$ & - & 4.28 & .72 & 3.77 & .86 \\
\hline
\end{tabular}

$* p<.05 ; * * p<.01$ 
$S D=.73)$, social support $(M=4.02, S D=.88)$ and job training $(M=3.82, S D=.85)$ than women $(M=4.58, S D=.53 ; M=$ 4.27, $S D=.82 ; M=4.06, S D=.72)$.

Regarding nationality, we found significant differences in needs covered $(t=4.89, p<.001)$, social support $(t=5.11$, $p<.001)$ and social integration $(t=7.17, p<.001)$. Foreigners presented lower scores in needs covered $(M=$ 4.34, $S D=.72)$, social support $(M=3.96, S D=.87)$ and social integration $(M=3.76, S D=.85)$ than Spanish nationals $(M=$ 4.62, $S D=.52 ; M=4.35, S D=.80 ; M=4.28, S D=.72)$.

Regarding religion, we found significant differences in needs covered $\left(F_{(3,470)}=8.54, p<.001\right)$, social support $\left(F_{(3,470)}=4.04, p=.007\right)$ and social integration $\left(F_{(3,470)}=\right.$ $6.50, p<.001)$. In the case of needs covered, Muslims $(M=$ 4.23, $S D=.81)$ presented lower scores than Christians $(M=$ $4.58, S D=.53)$ and non-believers $(M=4.50, S D=.55)$. In the case of social support, Muslims $(M=3.98, S D=.88)$ presented lower scores than Christians $(M=4.27, S D=.81)$. Finally, in the case of social integration, members of other religions $(M=3.45, S D=1.15)$ presented lower scores than Christians $(M=4.13, S D=.74)$ and Muslims $(M=4.01, S D=.85)$, while non-believers $(M=3.79, S D=.96)$ also presented lower scores than Christians.

\section{Discussion}

The results supported the five-factor structure in a sample of Spanish and foreign adolescents. The measurement invariance's test indicated that the pattern of association of the items in each of the theorized factors and the factor loadings of the items associated with each factor were similar for Spanish and foreign adolescents. However, the intercepts of both groups were different. As in the previous studies, all factors presented medium and strong correlations with the total mean score of the scale. Finally, men, foreigners, and members of religions other than Christianity, especially Muslims, were more susceptible to being at risk of social exclusion.

\section{General Discussion}

Despite its relevance, one of the most striking shortcomings in scientific research on social inclusion is that there have not been many occasions in which accurate, reliable, and solid measures have been used for its evaluation. Therefore, we aim to overcome this limitation by adopting an empirical approach to the study of some factors that are potentially contributing to this phenomenon. Specifically, the overall objective of this research was to develop an instrument to assess social inclusion, which we called the Social Inclusion for Adolescents Scale (SIAS). The following potentially underlying factors of social inclusion were specified: (1) covered needs; (2) self-efficacy; (3) social support; (4) job training; and (5) social integration. We could consider that the initially proposed objectives were achieved and that this scale represents an interesting approach to investigate the psychosocial factors contributing to social inclusion.

Taking the three studies into account, the sample size, the objectives for which it was used, and the conceptual complexity of the analyzed dimensions, it is considered that the psychometric properties of the instrument and, thus, of the measure it generates are quite acceptable. In the first study, the exploratory factor analysis showed that the different items factored in five dimensions as proposed. In the second study, a confirmatory factor analysis revealed that a structure with five dimensions or factors fitted better than a unifactorial solution. Finally, in the third study, it was verified that this structure fitted a sample of Spaniards and a sample of foreigners in a similar way. However, the measurement invariance's test showed that, while the factorization of the items was similar in both groups, the intercepts were different.

Regarding the internal consistency, the different analyses showed that the scale presented high reliability $(.86<\alpha<.88)$, while the internal consistency of the different factors presented more variability $(.63<\alpha<.84)$, with some factors only reaching reasonable reliability. Although for some factors the internal consistency was lower (in particular, under .70 only for social integration in some cases), as a whole, the internal consistency of the scale presents is more than acceptable, and its use in future studies should determine the adequacy of each of the factors. Likewise, the internal convergent validity between the different factors was shown to be adequate, presenting medium and strong correlations between them in the different studies. These results indicate a certain degree of independence among the factors, supporting the five-factor solution.

Finally, taking into account differences based on gender, nationality and religion, some patterns were in line with the literature and some were unexpected. Firstly, concerning gender, men repeatedly showed less social support than women, while women showed less self-efficacy than men. Men also had lower scores on needs covered and job training in some but not all studies. As we expected the level of inclusion perceived by women to be worse (Rúa et al., 2019), these results were partially unexpected. However, these results reflect the importance of using different dimensions when assessing the social exclusion-inclusion continuum and provide further support for the scale. These consistent results could indicate that men and women are both more vulnerable depending on the dimensions being assessed.

In terms of nationality, foreigners presented a lower level of inclusion in the needs covered, social support and social integration on a repeated basis. These indicators reflect exclusion and isolation in slum neighborhoods, where communication with the local people is lower, creating a differentiated and polarized identity (Lyons-Padilla, Gelfand, Mirahmadi, 
Farooq, \& van Egmond, 2015). Relative deprivation and competitiveness for obtaining certain resources can favour the development of asocial behaviours and the division of society (Moyano \& Trujillo, 2014a, b; Moyano \& Trujillo, 2016). All these factors are especially important when it comes to young people, who, of all social groups, are among the most vulnerable to exclusion and marginalization (Hargie, O'Donnell, \& McMullan, 2011).

Regarding religion, the same pattern was found, with nonChristians presenting lower levels of inclusion in needs covered, social support and social integration. In the short term, this may lead to frustration, poor mood, and asocial behaviours, while, in the long term, this could culminate in marginalization (Bélanger et al., 2019; Lyons-Padilla et al., 2015). As expected, those who did not conform to the majority's terms (i.e., Spanish nationality and Christian religion) presented worse levels of inclusion (Rúa et al., 2019).

For several reasons, we consider that this instrument covers an existing gap in the research on social inclusion (Baumgartner \& Burns, 2014; Cordier et al., 2017; Van Bergen et al., 2019). Firstly, it is a specific instrument for adolescents, understandable and adapted to young people of this developmental stage. Secondly, it was validated with a cross-cultural approach, using samples from different social groups, cultures, and nationalities. Thirdly, it assumes a multidimensional approach, integrating five psychosocial factors that are consistent with previous investigations. Lastly, this instrument can be useful in psychosocial interventions. Thus, in addition to the possibility of being used for scientific research, it can be considered a relevant tool for politicians and first-line practitioners in decision making and diagnosis, whether administered as a questionnaire or as a compendium of key indicators for systematic observation.

The choice of analyzing adolescence, as an evolutionary stage, was fundamental, since we understand that all those preventive measures that are developed during this period will influence future social inclusion. We believe that the social and economic situation in which we are currently immersed, predictably aggravated by the COVID-19 pandemic, can further favour the processes of social exclusion of individuals and social groups. Social exclusion implies widespread disadvantages in education, employment and housing, together with poorer access to social institutions and the persistence of such disadvantages over time (Michaels, 2020; Tyler \& Schmitz, 2020). Specific characteristics, such as being a foreigner or Spanish, white or black, Christian or Muslim, and woman or man, can condition the chances of normalization and social inclusion of these adolescents. This tendency towards segregation tends to intensify the social vulnerability of the groups that are already in a situation of greater social disadvantage, mainly affecting the construction of their identity, their social networks, and their referents in school settings, labor and leisure time (Navas, Rojas, García, \& Pumares, 2007). Moreover, youth who delay independence, have little chance of joining the job market, cannot assume their family responsibilities, and enjoy excessive free time (usually associated with unemployment) will be vulnerable to exclusion and to other situations of psychosocial risk.

For the benefit of the community and greater prevention of social exclusion, both institutions and society should be oriented towards a greater understanding of other cultures, together with a perspective of integration rather than assimilation or social juxtaposition. Nevertheless, social exclusion is not just a problem of foreigners, but a problem of all members of the host society. Thus, it is necessary to adopt a holistic perspective (integrating minorities and majorities) when developing intervention projects and evaluation and diagnostic tools.

Therefore, we highlight the importance of having brief and easily applicable instruments that allow researchers and social intervention professionals to assess personal vulnerability to exclusion. That being said, although we have exclusion indicators related to macro and meso levels, this is not the case at a more micro, individual, and personal level. It is important to keep in mind that it will be at the individual level where people will be perceived as more or less included, and where they will have greater or fewer psychological resources to face possible complex, controversial and even threatening social situations.

\section{Limitations and Future Research}

For the development of the scale, a robust procedure applied in large samples was followed; however, the different studies have some limitations that could be overcome in future investigations. Firstly, the samples were cross-sectional, that is, repeated measures were not taken over time. Thus, future research should prove the test-retest reliability. Secondly, we used Spanish and foreigner groups, but these groups did not distinguish between different ages. Future studies should validate the age ranges in which the scale works best. Similarly, more specific groups of foreigners based on their nationality of origin should be taken into account. Thirdly, the scale did achieve the intended level of measurement invariance partially. The intercepts of the items differ by group. Thus, future research should be aimed at ensuring that the scale measurements in different groups are similar, in order to avoid biases that could stigmatize certain groups.

\section{Conclusions}

The Social Inclusion for Adolescents Scale (SIAS) proved to be a useful tool in assessing the social exclusion-inclusion continuum in youth. It is consistent with the initial theoretical approaches and it can be a useful tool to study the systematically contributing factors, as well as in political decision making and psychosocial interventions. 


\section{Statements}

The datasets generated and analyzed during this investigation are available from the corresponding author upon reasonable request.

Supplementary Information The online version contains supplementary material available at https://doi.org/10.1007/s12144-020-01201-5.

Funding This research was funded by the Centro Mixto UGR-MADOC (18/16), the Spanish Ministry of Economy and Competitiveness and the European Regional Development Fund (MINECOR/FEDER) (DER2015-63857-R), and the European Union's Internal Security Fund-Police (823683)

\section{Compliance with Ethical Standards}

Conflict of Interest All authors declare no conflict of interest.

Ethical Approval The research was approved by the School Council of the educational centers where the sample was recruited.

Informed Consent Informed consents were obtained from the participants and their parents.

\section{References}

Abebe, D. S., Tøge, A. G., \& Dahl, E. (2016). Individual-level changes in self-rated health before and during the economic crisis in Europe. International Journal for Equity in Health, 15(1), 1-8. https://doi. org/10.1186/s12939-015-0290-8.

Baumgartner, J. N., \& Burns, J. K. (2014). Measuring social inclusion-a key outcome in global mental health. International Journal of Epidemiology, 43, 354-364. https://doi.org/10.1093/ije/dyt224.

Bélanger, J. J., Moyano, M., Muhammad, H., Richardson, L., Lafrenière, M. A. K., McCaffery, P., Framand, K., \& Nociti, N. (2019). Radicalization leading to violence: A test of the $3 \mathrm{~N}$ model. Frontiers in Psychiatry, 10(42), 1-12. https://doi.org/10.3389/ fpsyt.2019.00042.

Brown, T. A. (2006). Confirmatory factor analysis for applied research. New York: Guilford.

Chakravarty, S. R., \& D'Ambrosio, C. (2006). The measurement of social exclusion. Review of Income and Wealth, 52(3), 377-398. https:// doi.org/10.1111/j.1475-4991.2006.00195.x.

Cheung, G. W., \& Rensvold, R. B. (2002). Evaluating goodness-of-fit indexes for testing measurement invariance. Structural Equation Modeling, 9(2), 233-255. https://doi.org/10.1207/ S15328007SEM0902 5 .

Chin, R. (2017). The crisis of multiculturalism in Europe: A history. New Jersey: Princeton University Press.

Cordier, R., Milbourn, B., Martin, R., Buchanan, A., Chung, D., \& Speyer, R. (2017). A systematic review evaluating the psychometric properties of measures of social inclusion. PLoS One, 12(6), e0179109. https://doi.org/10.1371/journal.pone.0179109.

Du, X., Xu, M., Ding, C., Yuan, S., Zhang, L., \& Yang, D. (2020). Social exclusion increases the visual working memory capacity of social stimuli. Current Psychology, 39, 1149-1160. https://doi.org/10. 1007/s12144-019-00274-1.

Duffy, K. (1995). Social exclusion and human dignity in Europe. Strasbourg: Council of Europe.
Esteban, J. M., \& Ray, D. (1994). On the measurement of polarization. Econometrica, 62(4), 819-851. https://doi.org/10.2307/2951734.

European Union Agency for Fundamental Rights (2019). Fundamental Rights Report 2019 (Research report). Retrieved from https://fra. europa.eu/en/publication/2019/fundamental-rights-2019

EUROSTAT. (2019). Europe 2020 indicators - poverty and social exclusion (Research report). Retrieved from https://ec.europa.eu/ eurostat/statistics-explained/index.php?title=Europe 2020 indicators_-_poverty_and_social_exclusion\#How_do_poverty_ and social exclusion affect Europe. $3 \mathrm{~F}$

Greven, $\overline{\mathrm{T}}$. (2016). The rise of right-wing populism in Europe and the United States: A comparative (Research report). Washington DC: Friedrich Ebert Foundation. Retrieved from https://library.fes.de/ pdf-files/id/12892.pdf

Hair, J. F., Anderson, R. E., Tatham, R. L., \& Black, W. C. (1999). Análisis multivariante [Multivariate analysis]. Madrid: Prentice Hall Iberia.

Hambleton, R. K. (1994). The rise and fall of criterion-referenced measurement? Educational Measurement: Issues and Practice, 13(4), 21-26. https://doi.org/10.1111/j.1745-3992.1994.tb00567.x.

Hargie, O., O'Donnell, A., \& McMullan, C. (2011). Constructions of social exclusion among young people from interface areas of Northern Ireland. Youth \& Society, 43(3), 873-899. https://doi.org/ 10.1177/0044118X10366950.

Huxley, P., Evans, S., Madge, S., Webber, M., Burchardt, T., McDaid, D., \& Knapp, M. (2012). Development of a social inclusion index to capture subjective and objective life domains (phase II): Psychometric development study. Health Technology Assessment, 16(1), 1-248. https://doi.org/10.3310/hta16010.

Instituto Nacional de Estadística (2019). Encuesta de condiciones de vida (ECV). Año 2018 (Research report) [Survey of living conditions (SLC). Year 2018]. Retrieved from https://www.ine.es/prensa/ecv 2018.pdf

Klasen, S. (2002). Social exclusion and children in OECD countries: Some conceptual issues. The School Field, 13, 9-25.

Kline, R. (2016). Principles and practice of structural equation modeling. New York: Guilford.

Lee, R. M., \& Robbins, S. B. (1995). Measuring belongingness: The social connectedness and the social assurance scales. Journal of Counseling Psychology, 42(2), 232-241. https://doi.org/10.1037/ 0022-0167.42.2.232.

Li, S., Zhao, F., \& Yu, G. (2018). Social exclusion and depression among college students: A moderated mediation model of psychological capital and implicit theories. Current Psychology. https://doi.org/ 10.1007/s12144-018-0036-Z.

Lord, F. M., \& Novick, M. R. (1968). Statistical theories of mental test scores. Reading, MA: Addison Wesley.

Lyons-Padilla, S., Gelfand, M. J., Mirahmadi, H., Farooq, M., \& van Egmond, M. (2015). Belonging nowhere: Marginalization and radicalization risk among Muslim immigrants. Behavioral Science \& Policy, 1(2), 1-12. https://doi.org/10.1353/bsp.2015.0019.

Michaels, E. (2020). Beyond academic achievement outcomes: The impact of school on the immigrant political incorporation of undocumented latinx youth. Youth \& Society, 52(7), 1285-1311. https:// doi.org/10.1177/0044118X20913733.

Moyano, M., \& Trujillo, H. M. (2014a). Evaluación del riesgo de radicalización islamista en cuatro contextos de interés estratégico para España [Risk assessment of Islamist radicalization in four contexts of strategic interest for Spain]. En F. Velasco y R. Arcos (Eds.), Estudios en inteligencia. Respuestas para la gobernanza democrática (pp. 105-124). Madrid: Ministerio de la Presidencia (Gobierno de España) y Ed. Plaza y Valdés.

Moyano, M., \& Trujillo, H. M. (2014b). Intention of activism and radicalism among Muslim and Christian youth in a marginal neighbourhood in a Spanish city / Intención de activismo y radicalismo de jóvenes musulmanes y cristianos residentes en un 
barrio marginal de una ciudad española. Revista de Psicología Social, 29(1), 90-120. https://doi.org/10.1080/02134748.2013. 878571.

Moyano, M., \& Trujillo, H. M. (2016). Incidentes críticos de violencia urbana vinculados al radicalismo islamista en España: Simulación y análisis de un escenario [Critical incidents of urban violence linked to Islamist radicalism in Spain: Simulation and analysis of a scenario]. Universitas Psychologica, 15(1), 193-204. https://doi.org/10. 11144/Javeriana.upsy15-1.icvu.

Navarro-Carrillo, G., Valor-Segura, I., \& Moya, M. (2019). The consequences of the perceived impact of the Spanish economic crisis on subjective well-being: The explanatory role of personal uncertainty. Current Psychology. https://doi.org/10.1007/s12144-019-00506-4.

Navas, M., Rojas, A. J., García, M., \& Pumares, P. (2007). Acculturation strategies and attitudes according to the relative acculturation extended model (RAEM): The perspectives of natives versus immigrants. International Journal of Intercultural Relations, 31(1), 6786. https://doi.org/10.1016/j.ijintrel.2006.08.002.

OECD (2019). OECD employment outlook 2019 (Research report). Organisation for economic co-operation and development. Retrieved from https://www.oecd.org/employment/outlook/

Paugam, S., \& Russell, H. (2000). The effects of employment precarity and unemployment on social isolation. In D. Gallie y S. Paugam (Eds.), Welfare regimes and the experience of social isolation (pp. 243-265). Oxford: Oxford University Press.

Pirani, E. (2013). Evaluating contemporary social exclusion in European hierarchical latent class approach. Quality \& Quantity, 47, 923-941. https://doi.org/10.1007/s11135-011-9574-2.

Postelnicescu, C. (2016). Europe's new identity: The refugee crisis and the rise of nationalism. Europe's Journal of Psychology, 12(2), 203 209. https://doi.org/10.5964/ejop.v12i2.1191.

Room, G. (Ed.). (1995). Beyond the threshold: The measurement and analysis of social exclusion. Bristol: The Policy Press.

Rosseel, Y. (2012). Lavaan: An R package for structural equation modeling. Journal of Statistical Software, 48(2), 1-36.

Rúa, A., Martínez, C., Redondo, R., Ortiz, J. M., \& Fabra, M. E. (2019). Informe sobre la vulnerabilidad social 2018 [Social vulnerability report 2018] (Research report). Madrid: Cruz Roja Española. Retrieved from https://repositorio.comillas.edu/xmlui/bitstream/ handle/11531/36260/informevs2018.pdf? sequence $=-$ $1 \&$ isAllowed=y
Satorra, A., \& Bentler, P. M. (2001). A scaled difference chi-square test statistic for moment structure analysis. Psychometrika, 66(4), 507514. https://doi.org/10.1007/BF02296192.

Secker, J., Hacking, S., Kent, L., Shenton, J., \& Spandler, H. (2009). Development of a measure of social inclusion for arts and mental health project participants. Journal of Mental Health, 18(1), 65-72. https://doi.org/10.1080/09638230701677803.

Taber, K. S. (2018). The use of Cronbach's alpha when developing and reporting research instruments in science education. Research in Science Education, 48(6), 1273-1296. https://doi.org/10.1007/ s11165-016-9602-2.

Tholen, B., \& De Vries, M. S. (2004). The inclusion and exclusion of minorities in European countries: A comparative analysis at the local level. International Review of Administrative Sciences, 70, 455476. https://doi.org/10.1177/0020852304046201.

Tsakloglou, P., \& Papadopoulos, F. (2002). Aggregate level and determining factors of social exclusion in twelve European countries. Journal of European Social Policy, 12(3), 211-225. https://doi. org/10.1177/0952872002012003394.

Tyler, K. A., \& Schmitz, R. M. (2020). Childhood disadvantage, social and psychological stress, and substance use among homeless youth: A life stress framework. Youth \& Society, 52(2), 272-287. https:// doi.org/10.1177/0044118X18767032.

UNHCR. The United Nations Refugee Agency. (2019). Global Trends. Forced displacement in 2018 (Research report). Retrieved from https://www.unhcr.org/globaltrends2018/

Van Bergen, A. P., Wolf, J. R., Badou, M., de Wilde-Schutten, K., IJzelenberg, W., Schreurs, H., ... \& van Hemert, A. M. (2019). The association between social exclusion or inclusion and health in EU and OECD countries: A systematic review. European Journal of Public Health, 29(3), 575-582. https://doi.org/10.1093/ eurpub/cky143.

Van Regenmortel, S., De Donder, L., Dury, S., Smetcoren, A. S., De Witte, N., \& Verté, D. (2016). Social exclusion in later life: A systematic review of the literature. Journal of Population Ageing, 9(4), 315-344. https://doi.org/10.1007/s12062-016-9145-3.

Publisher's Note Springer Nature remains neutral with regard to jurisdictional claims in published maps and institutional affiliations. 